\title{
Pioglitazone Ameliorates Acute Endotoxemia-Induced Acute on Chronic Renal Dysfunction in Cirrhotic Ascitic Rats
}

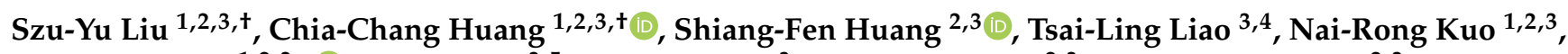 \\ Ying-Ying Yang ${ }^{1,2,3, * \mathbb{D}}$, Tzu-Hao $\mathrm{Li}^{3,5}$, Chih-Wei Liu ${ }^{3}$, Ming-Chih $\mathrm{Hou}^{2,3}$ and Han-Chieh Lin ${ }^{2,3, *}$ \\ 1 Department of Medical Education, Medical Innovation and Research Office (MIRO), \\ Taipei Veterans General Hospital, Taipei 11217, Taiwan; maru2637@gmail.com (S.-Y.L.); \\ cchuang7@vghtpe.gov.tw (C.-C.H.); knairong@gmail.com (N.-R.K.) \\ 2 Department of Medicine, Taipei Veterans General Hospital, Taipei 11217, Taiwan; \\ sfhuang6@vghtpe.gov.tw (S.-F.H.); mchou@vghtpe.gov.tw (M.-C.H.) \\ 3 Faculty of Medicine, School of Medicine, National Yang-Ming Chiao Tung University, Taipei 11217, Taiwan; \\ tlliao@vghtc.gov.tw (T.-L.L.); pearharry@yahoo.com.tw (T.-H.L.); cwliu2@vghtpe.gov.tw (C.-W.L.) \\ 4 Department of Medical Research, Taichung Veterans General Hospital, Taichung 11217, Taiwan \\ 5 Division of Allergy, Immunology, and Rheumatology, Department of Internal Medicine, \\ Shin Kong Wu Ho-Su Memorial Foundation, Taipei 11217, Taiwan \\ * Correspondence: yangyy@vghtpe.gov.tw (Y.-Y.Y.); hclin@vghtpe.gov.tw (H.-C.L.); \\ Tel.: +886-02-28712121-7110 (Y.-Y.Y.) \\ + These two authors shared the first authorship of this manuscript.
}

check for updates

Citation: Liu, S.-Y.; Huang, C.-C.; Huang, S.-F.; Liao, T.-L.; Kuo, N.-R.; Yang, Y.-Y.; Li, T.-H.; Liu, C.-W.; Hou, M.-C.; Lin, H.-C. Pioglitazone Ameliorates Acute EndotoxemiaInduced Acute on Chronic Renal Dysfunction in Cirrhotic Ascitic Rats. Cells 2021, 10, 3044. https:/ / doi.org/10.3390/cells10113044

Academic Editor: Giovanni Camussi

Received: 23 October 2021

Accepted: 3 November 2021

Published: 5 November 2021

Publisher's Note: MDPI stays neutral with regard to jurisdictional claims in published maps and institutional affiliations.

Copyright: (c) 2021 by the authors. Licensee MDPI, Basel, Switzerland. This article is an open access article distributed under the terms and conditions of the Creative Commons Attribution (CC BY) license (https:// creativecommons.org/licenses/by/ $4.0 /)$.
Abstract: Endotoxemia-activated tumor necrosis factor $(\mathrm{TNF} \alpha)$ /nuclear factor kappa B (NFkB) signals result in acute on chronic inflammation-driven renal dysfunction in advanced cirrhosis. Systemic activation of peroxisome proliferator-activated receptor gamma (PPAR $\gamma$ ) with pioglitazone can suppress inflammation-related splanchnic and pulmonary dysfunction in cirrhosis. This study explored the mechanism and effects of pioglitazone treatment on the abovementioned renal dysfunction in cirrhotic rats. Cirrhotic ascitic rats were induced with renal dysfunction by bile duct ligation (BDL). Then, 2 weeks of pioglitazone treatment (Pio, PPAR gamma agonist, $12 \mathrm{mg} / \mathrm{kg} /$ day, using the azert osmotic pump) was administered from the 6th week after BDL. Additionally, acute lipopolysaccharide (LPS, Escherichia coli 0111:B4; Sigma, $0.1 \mathrm{mg} / \mathrm{kg}$ b.w, i.p. dissolved in $\mathrm{NaCl} \mathrm{0.9 \% )} \mathrm{was} \mathrm{used}$ to induce acute renal dysfunction. Subsequently, various circulating, renal arterial and renal tissue pathogenic markers were measured. Cirrhotic BDL rats are characterized by decreased mean arterial pressure, increased cardiac output and portal venous pressure, reduced renal arterial blood flow (RABF), increased renal vascular resistance (RVR), increased relative renal weight/hydroxyproline, downregulated renal PPAR $\gamma$ expression, upregulated renal inflammatory markers (TNF $\alpha, N F \kappa B$, IL-6, MCP-1), increased adhesion molecules (VCAM-1 and ICAM-1), increased renal macrophages (M1, CD68), and progressive renal dysfunction (increasing serum and urinary levels of renal injury markers (lipocalin-2 and IL-18)). In particular, acute LPS administration induces acute on chronic renal dysfunction (increasing serum BUN/creatinine, increasing RVR and decreasing RABF) by increased TNF $\alpha$-NFKB-mediated renal inflammatory markers as well as renal M1 macrophage infiltration. In comparison with the BDL+LPS group, chronic pioglitazone pre-treatment prevented LPS-induced renal pathogenic changes in the BDL-Pio+LPS group. Activation of systemic, renal vessel and renal tissue levels of PPAR $\gamma$ by chronic pioglitazone treatment has beneficial effects on the endotoxemia-related TNF $\alpha / \mathrm{NF}_{\kappa} \mathrm{B}$-mediated acute and chronic renal inflammation in cirrhosis. This study revealed that normalization of renal and renal arterial levels of PPAR $\gamma$ effectively prevented LPS-induced acute and chronic renal dysfunction in cirrhotic ascitic rats.

Keywords: endotoxemia; lipopolysaccharide; pioglitazone; cirrhosis; PPAR $\gamma$; TNF $\alpha$ 


\section{Introduction}

In cirrhosis, endotoxemia-activated tumor necrosis factor $\alpha$ (TNF $\alpha) / N F \kappa B$ signals are involved in the development of systemic, pulmonary, splanchnic and renal dysfunction [1-3]. In cirrhotic kidneys, acute accumulation of lipopolysaccharide (LPS, endotoxin) results in $\mathrm{TNF} \alpha / \mathrm{NF} \kappa \mathrm{B}-$-mediated hypoperfusion and inflammation-driven acute on chronic renal dysfunction by increasing renal adhesion molecule, increasing renal M1 macrophage infiltration, decreasing renal blood flow (RABF), increasing renal vascular resistance (RVR), and increasing renal tissue/renal vascular inflammation [4-8].

Endotoxemia-related renal inflammation is characterized by a reduction in RABF in septic rats [8]. Endotoxin and TNF $\alpha / \mathrm{NF} \kappa \mathrm{B}$ are involved in the RABF decline and chronic renal dysfunction in bile-duct ligated rats $[9,10]$. In healthy rats, the infusion of TNF $\alpha$ lowers RABF and increases RVR by inducing vascular inflammation without affecting arterial pressure [11,12]. In cirrhotic ascitic patients, decreasing the levels of circulating endotoxin and TNF $\alpha$ using selective intestinal decontamination with rifaximin improved chronic renal dysfunction [13]. During renal vascular inflammation, a significant (around $40 \%$ ) reduction in RABF and chronic renal dysfunction were reported in compensated cirrhotic patients compared to those in healthy volunteers [1]. PPAR $\gamma$ is expressed in renal medullary interstitial cells in the juxtaglomerular apparatus and glomeruli, including podocytes, mesangial cells, and renal microvascular endothelial cells [14]. Given that multiple renal cell types have endogenous PPAR $\gamma$ expression and activity, its activation in the kidney may be critical for governing renal function. In mice with diabetic nephropathy, chronic pioglitazone treatment decreases both renal vascular inflammation and reduces RVR [15].

Decreased pulmonary expression of PPAR $\gamma$ accelerated the ongoing endotoxemiarelated $\mathrm{TNF} \alpha / \mathrm{NF} \kappa \mathrm{B}-$ mediated lung inflammation and injury [16]. In septic rats, pharmacological activation of PPAR $\gamma$ attenuates endotoxin-induced TNF $\alpha /$ NFKB-mediated renal injury and dysfunction $[17,18]$. Activation of PPAR $\gamma$ with pioglitazone reduces renal macrophage infiltration $[19,20]$.

Activation of endothelial PPAR $\gamma$ with PPAR $\gamma$ agonist rosiglitazone inhibits LPSinduced vascular inflammation [21]. Pioglitazone is a nuclear receptor PPAR $\gamma$ activator that exerts anti-inflammatory effects by antagonizing LPS-mediated vascular inflammation [22]. Downregulated hepatic PPAR $\gamma$ expression is associated with increased systemic circulating inflammatory cytokines in BDL rats [23]. In BDL-cirrhotic rats, chronic pioglitazone treatment attenuates motor and cognition impairments and suppresses TNF $\alpha / \mathrm{NF} K \mathrm{~B}$-mediated inflammation-related portosystemic shunting and hepatopulmonary syndrome [24-26].

Taken together, the effects of chronic pioglitazone treatment on endotoxemia-induced cirrhosis-related acute on chronic vascular and tissue inflammation-related renal dysfunction have not been explored. This study evaluated the mechanism and effects of activation of systemic, renal tissue and renal vascular levels of PPAR $\gamma$ by chronic pioglitazone treatment on the TNF $\alpha / \mathrm{NFkB}$-mediated acute on chronic renal dysfunction in cirrhotic ascitic rats.

\section{Materials and Methods}

\subsection{Methods}

Common bile duct ligation (BDL) was conducted on adult male Sprague-Dawley rats (300-350 g), as described previously [2,5,10,24]. All animal experiments were approved by the Animal Care Committee of the National Yang-Ming Chiao Tung University (YMCU) and conducted in the animal facilities of YMCU with No. 1090211r which was approved on 1 January 2020. All efforts were made to minimize the number of animals necessary to produce reliable results, and suffering was reduced by administering anesthetics (zoletil and xylocaine). At the end of the experiments, the rats were euthanized using a 2-3 times high anesthetic dose of zoletil.

To evaluate the effects of chronic pioglitazone (Pio, PPAR gamma agonist, $12 \mathrm{mg} / \mathrm{kg} /$ day, using the azert osmotic pump for intraperitoneal administration) or DMSO (a substance 
used to dissolve pioglitazone), pre-treatment on LPS was used to induce acute on chronic renal injury of cirrhotic rats. Four weeks after BDL, cirrhotic rats were randomized to receive two weeks of pioglitazone before the acute LPS challenge. Without modifying blood sugar levels, this dose of chronic pioglitazone treatment can ameliorate splanchnic inflammation, decrease portosystemic shunting, and prevent hepatopulmonary syndrome in cirrhotic animals [24-26]. Then, to induce an acute renal dysfunction, rats were randomly allocated 6 weeks after BDL to receive an intraperitoneal injection of LPS (Escherichia coli 0111:B4; Sigma, $0.1 \mathrm{mg} / \mathrm{kg}$ b.w, i.p. dissolved in $\mathrm{NaCl} \mathrm{0.9 \% ).} \mathrm{Subsequently,} \mathrm{various}$ parameters were measured $3 \mathrm{~h}$ after LPS administration. The experimental groups were sham $(n=4)$, sham+LPS $(n=4)$, sham-Pio+LPS $(n=4), \operatorname{BDL}(n=9), \operatorname{BDL}+\operatorname{LPS}(n=9)$, and $\operatorname{BDL}-\mathrm{Pio}+\mathrm{LPS}(n=9)$ rats.

\subsection{Urine Sample Collection}

In order to evaluate the effects of chronic pioglitazone treatment on progressive cirrhosis-related renal injury, urinary renal tubular epithelial damage markers (uLipocalin-2, uIL-18 and creatinine (Colorimetric kits purchased by Cayman Chemical)) were measured in urine collected daily at 1-2, 15-16, 29-30, and 43-44 days after BDL. All the measurements and acute LPS infusion were conducted after the last daily urine collection. To collect urine, the rats were first caged in $24 \mathrm{~h}$ metabolic cages for 2 days of acclimatization to reduce separation effects.

\subsection{Hemodynamic Measurements in the Days of Tissue Collections}

Tissue and blood samples were collected after various hemodynamic measurements (mean arterial pressure (MAP), cardiac output $(\mathrm{CO})$, heart rate $(\mathrm{HR})$, bilateral RABF (mL/min·100 g body weight, BW), and portal venous pressure (PVP)). The right renal artery was identified at its aortic origin, and a $5 \mathrm{~mm}$ segment was gently dissected from the surrounding tissues. A pulsed-Doppler flow transducer (T206 small animal blood flowmeter; Transonic Systems, Ithaca, NY, USA) was then placed to measure the renal artery blood flow rate. Following a $1 \mathrm{~h}$ equilibrium period, the RABF was measured for $1 \mathrm{~h}$. The results are reported as $\mathrm{mL} / \mathrm{min}$. Extrarenal renal vascular resistance (RVR) was calculated as MAP/RABF. The cardiac index (CI) was calculated using the following formula: $\mathrm{CI}=\mathrm{CO} / \mathrm{BW}$. Stroke volume (SV; $\mathrm{mL} /$ beats) was calculated as $(\mathrm{CO}(\mathrm{mL} / \mathrm{min}) / \mathrm{HR}$ (beats/min))).

\subsection{Measurement of Various Plasma Pathogenic Factors}

Blood was obtained from the inferior vena cava at the time of euthanasia. Plasma levels of biochemical parameters were determined using an automated biochemistry analyzer (Olympus, Tokyo, Japan). Additionally, serum samples were analyzed for TNF- $\alpha$ and IL-6 levels by enzyme-linked immunosorbent assay according to the manufacturer's instructions (BioSource International, Camarillo, CA, USA).

\subsection{Isolated Renal Perfusion Study}

All rats were anesthetized intraperitoneally with zoletil (50 mg/ $\mathrm{kg}$ body weight, ip) and fixed in the supine position. The isolated renal perfusion study of the right kidney was conducted as previously described $[10,12]$. In the rat perfusion system, RVR was recorded using a pressure transducer (Gould, Oxnard, CA, USA) as changes in renal perfusion pressure (RPP) downstream from the pump. RVR (mm Hg/mL per min/g) was calculated from the ratio of constant perfusion flow to the RPP. Once the RPP reached its steady state, experiments were initiated by the addition of cumulative concentrations of $\operatorname{TNF} \alpha(0.1,0.3$, and $0.5 \mathrm{ng} / \mathrm{g} / \mathrm{min})$ to the perfusion apparatus with Krebs-Henseleit solution inside. Different concentrations of TNF $\alpha$ were added after the previous response reached a maximum. 


\subsection{Tissue Profiles}

All renal arteries (including renal, lobar, and arcuate arteries) and kidneys were collected, immediately frozen in liquid nitrogen, and stored at $-80{ }^{\circ} \mathrm{C}$ until analysis. In addition to immunochemistry and immunofluorescence staining, periodic acid-Schiff (PAS)-stained and Sirius Red-stained renal sections were also prepared to evaluate the severity of renal tubular damage and tubulointerstitial fibrosis.

\subsection{Flow Cytometry}

For measuring macrophage infiltration, the cell pellets of renal tissue were washed in FACS buffer for staining with F4/80-FITC, CD11c-PE, and CD206-AF488 antibodies (BD Biosciences, Franklin Lakes, NJ, USA) and incubated on ice for $1 \mathrm{~h}$. After the wells were washed in FACS buffer, they were re-suspended in $500 \mu \mathrm{L}$ of FACS and analyzed with a FACS Calibur flow cytometer; the resulting data were analyzed using the FlowJo software (Tree Star, Ashland, OR, USA). Fluorescence voltages were determined using matched unstained cells. Two hundred thousand events were acquired in a live mononuclear gate. Then, the number of M1 (F4/80(+)/CD11c(+)) and M2 (F4/80(+)/CD206(+)) macrophages in $1 \mathrm{~mL}$ of tissue homogenates was obtained.

\subsection{Materials}

Antibodies against TNF $\alpha$, IL-6, CD68, CD163, MCP-1, F4/80-FITC, CD11c-PE, and CD206-AF488 were purchased from Cell Signaling Technology (Danvers, MA, USA) and Santa Cruz Biotechnology (Santa Cruz, CA, USA). Primers (Table 1) of TNF $\alpha$, MCP-1, IL-4, IL-13 and 18S were purchased from Applied Biosystems. All other reagents were obtained from Sigma (St. Louis, MO, USA). Tissue levels of the adhesion molecules ICAM-1, VCAM-1 and MCP-1 were measured by enzyme-linked immunosorbent assay (ELISA) using commercially available ELISA kits (BD Bioscience, San Jose, CA, USA).

Table 1. Primers of various genes.

\begin{tabular}{|c|c|c|}
\hline Gene Name & Forwards & Reverse \\
\hline $\mathrm{TNF} \alpha$ & 5'-GCT CAC AAT GTC TGT GCT TAGAG-3' & 5'-GCA GTA GCC ACA GCT CCAG-3' \\
\hline MCP-1 & 5'-ATG CAG TTA ATG CCC CAC TC-3' & 5'-TGC TGC TGG TGA TTG TCT TG-3' \\
\hline IL-4 & $5^{\prime}$-GGA TGT GCC AAA CGT CCT C-3' & 5'-GAG TTC TTC TTC AAG CAT GGAG-3' \\
\hline IL-13 & 5'-CTT TCT TTA GCG GCC AC-3 & $5^{\prime}$-CAG AGC GCC ATG AAG CCC AGAG-3' \\
\hline $18 \mathrm{~S}$ & $5^{\prime}$-ACGGAAGGGCACCACCAGGA-3' & 5'-CACCACCACCCACGGAATCG-3 \\
\hline
\end{tabular}

$\mathrm{TNF} \alpha$ : tumor necrosis factor $\alpha$ (TNF $\alpha$ ); MCP-1: monocyte chemoattractant protein-1; IL-4: interleukin-4; IL-13: interleukin-13.

\subsection{Statistical Analysis}

All values are expressed as the mean \pm standard error of the mean (SEM). Differences between groups were compared using Mann-Whitney $U$ test for the comparison of the data of mean/SEM, and differences between two groups and ANOVA with post-hoc test for comparison among multiple groups. Statistical significance was set at $p<0.05$.

\section{Results}

3.1. Cirrhotic BDL Rats Are Characterized by Progressive Renal Dysfunction that Can Be Attenuated by Chronic Pioglitazone Treatment

In comparison with sham rats, cirrhotic rats were characterized by decreased MAP, increased CO and PVP, reduced RABF, increased RVR, increased relative renal weight and increased renal hydroxyproline levels (Table 2). Although not reaching significance, acute LPS administration showed a decreasing MAP and CO and increasing PVP and RABF. Acute on chronic renal dysfunction (increased blood urea nitrogen and creatinine, Figure 1C,D) were observed in BDL+LPS groups. Notably, the relative kidney weight and renal hydroxyproline were not different between the sham, sham+LPS, BDL, and BDL+LPS groups. In comparison with the sham group, a serial increase in renal injury markers (IL-18 and 
lipocalin-2) in urine and renal tissue were observed (Figures $1 \mathrm{~A}, \mathrm{~B}$ and $2 \mathrm{~A}$ ) in BDL groups. This observation indicated that progressive injury-related renal dysfunction existed in rat cirrhotic kidneys two weeks after BDL. In the BDL-Pio+LPS group, before LPS administration, the urinary levels of IL-18 and lipocalin-2 were lower than those in the BDL group (Figure 1A,B). These results indicated that the two weeks of pioglitazone treatment attenuated progressive renal dysfunction as well as acute LPS-deteriorated renal function in cirrhotic rats. Additionally, this pre-treatment attenuated the LPS-induced decrease in MAP and $\mathrm{CO}$ and the increase in RABF, serum BUN, and serum creatinine in the BDL-Pio+LPS group (Table 2 and Figure 1C,D).

Table 2. Hemodynamic parameters of cirrhotic rats receiving chronic pioglitazone treatments after acute LPS infusion.

\begin{tabular}{|c|c|c|c|c|c|c|}
\hline & $\begin{array}{l}\text { Sham } \\
(n=4)\end{array}$ & $\begin{array}{c}\text { Sham + LPS } \\
(n=4)\end{array}$ & $\begin{array}{c}\text { Sham-Pio+LPS } \\
(n=4)\end{array}$ & $\begin{array}{l}\text { BDL } \\
(n=9)\end{array}$ & $\begin{array}{c}\text { BDL+LPS } \\
(n=9)\end{array}$ & $\begin{array}{c}\text { BDL-Pio+LPS } \\
(n=9)\end{array}$ \\
\hline MAP (mmHg) & $110 \pm 14$ & $106 \pm 9$ & $109 \pm 11$ & $92 \pm 12$ * & $87 \pm 5^{\#}$ & $90 \pm 6$ \\
\hline $\begin{array}{c}\text { Cardiac output }(\mathrm{CO}, \\
\mathrm{mL} / \mathrm{min})\end{array}$ & $229 \pm 38$ & $203 \pm 28$ & $211 \pm 19$ & $259 \pm 41 *$ & $212 \pm 29 \#$ & $242 \pm 33$ \\
\hline PVP (mmHg) & $7.8 \pm 0.9$ & $9.1 \pm 0.6$ & $8.2 \pm 0.8$ & $17.3 \pm 1.6$ * & $18.2 \pm 2.3$ & $17.9 \pm 2.1$ \\
\hline $\mathrm{RABF}(\mathrm{mL} / \mathrm{min} \cdot 100 \mathrm{~g})$ & $5.1 \pm 1.4$ & $5.6 \pm 1.6$ & $5.4 \pm 1.2$ & $3.0 \pm 1.3 *$ & $3.8 \pm 0.5$ & $3.6 \pm 0.9$ \\
\hline $\begin{array}{l}\text { Body weight } \\
\text { (BW, gram) }\end{array}$ & $354.6 \pm 18.4$ & $349.8 \pm 16.5$ & $347.2 \pm 13.9$ & $306.4 \pm 21.4$ * & $309.3 \pm 18.9$ & $310.2 \pm 14.3$ \\
\hline $\begin{array}{l}\text { Kidney weight (KW, } \\
\text { both sides, grams) }\end{array}$ & $1.25 \pm 0.007$ & $1.22 \pm 14.8$ & $1.21 \pm 0.018$ & $1.9 \pm 0.078$ & $2.1 \pm 0.065$ & $1.4 \pm 0.009$ \\
\hline $\mathrm{KW} / \mathrm{BW}\left(10^{-3}\right)$ & $0.36 \pm 0.0021$ & $0.35 \pm 0.003$ & $0.35 \pm 0.007$ & $0.62 \pm 0.004$ * & $0.68 \pm 0.003$ & $0.45 \pm 0.002^{\#}$ \\
\hline $\begin{array}{l}\text { Renal hydroxyproline } \\
(\mu \mathrm{g} / \mathrm{mg} \text { kidney })\end{array}$ & $312 \pm 22$ & $309 \pm 27$ & $310 \pm 19$ & $429 \pm 12$ * & $418 \pm 17$ & $420 \pm 8$ \\
\hline
\end{tabular}

In sham-LPS or BDL-LPS groups, all measurements were undergone $3 \mathrm{~h}$ after LPS infusion; ${ }^{*} p<0.05$ vs. sham group; ${ }^{\#} p<0.05 \mathrm{vs.} \mathrm{BDL}$ group. MAP: mean arterial pressure; portal venous pressure (PVP); RABF: renal artery blood flow is the summation of right and left side kidney.
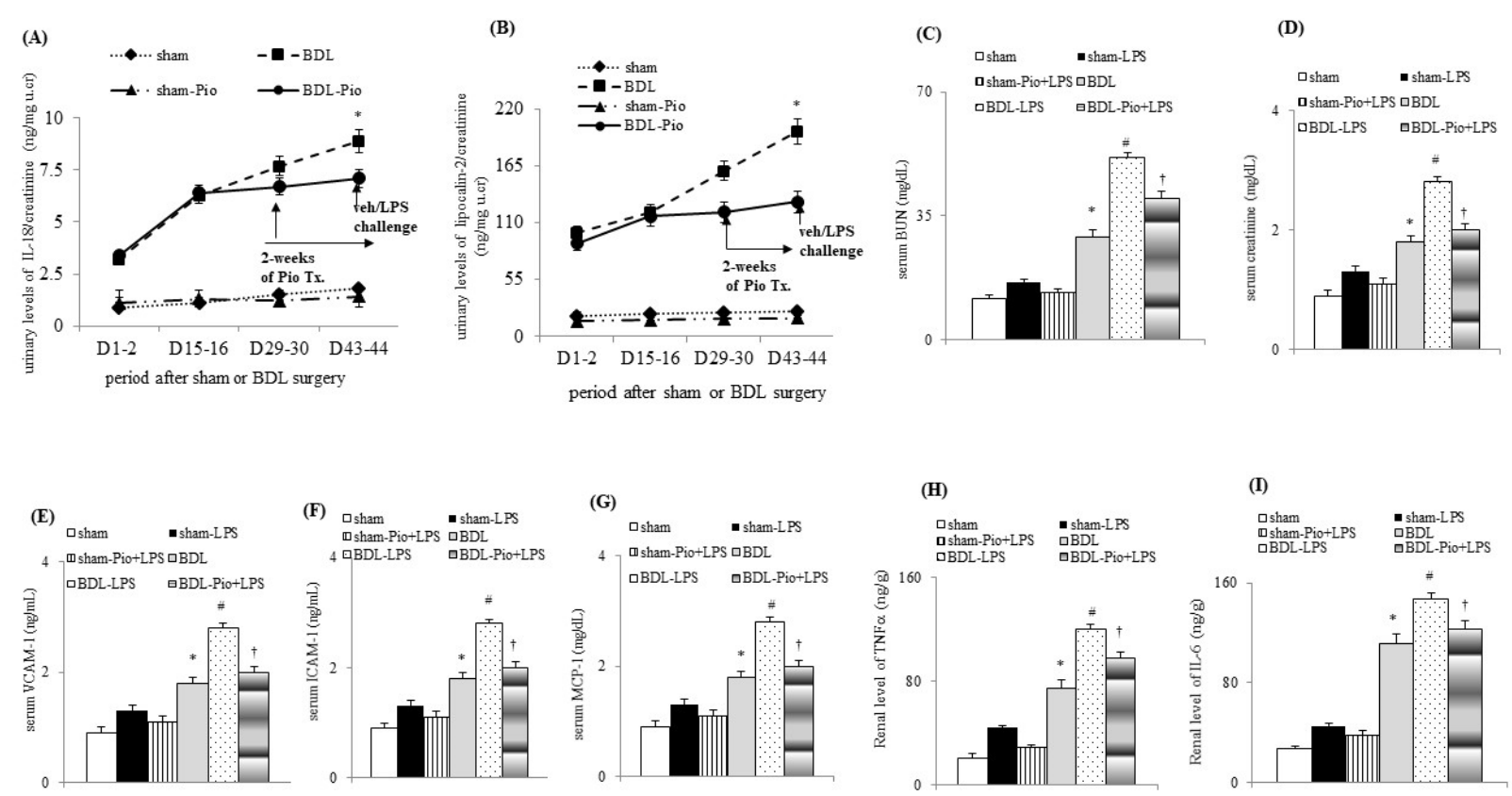

Figure 1. Chronic piogliotazone treatment attenuated chronic renal dysfunction in cirrhotic rats. (A,B) Urinary levels of renal injury markers including interleukin-18 (IL-18) and lipocalin-2; (C,D) serum BUN and creatinine; serum levels of (E) vascular cell adhesion molecule-1 (VCAM-1), (F) intracellular adhesion molecule-1 (ICAM-1), (G) monocyte chemoattractant protein-1 (MCP-1); renal levels of (H) TNF $\alpha$, tumor necrosis factor $\alpha(\mathrm{TNF} \alpha)$ and (I) interleukin-6 (IL-6); ${ }^{*} p<0.05$ sham vs. BDL group; $\# p<0.05$ vs. BDL vs. BDL-LPS group; $\uparrow p<0.05$ vs. BDL-pio+LPS vs. BDL-LPS group. 

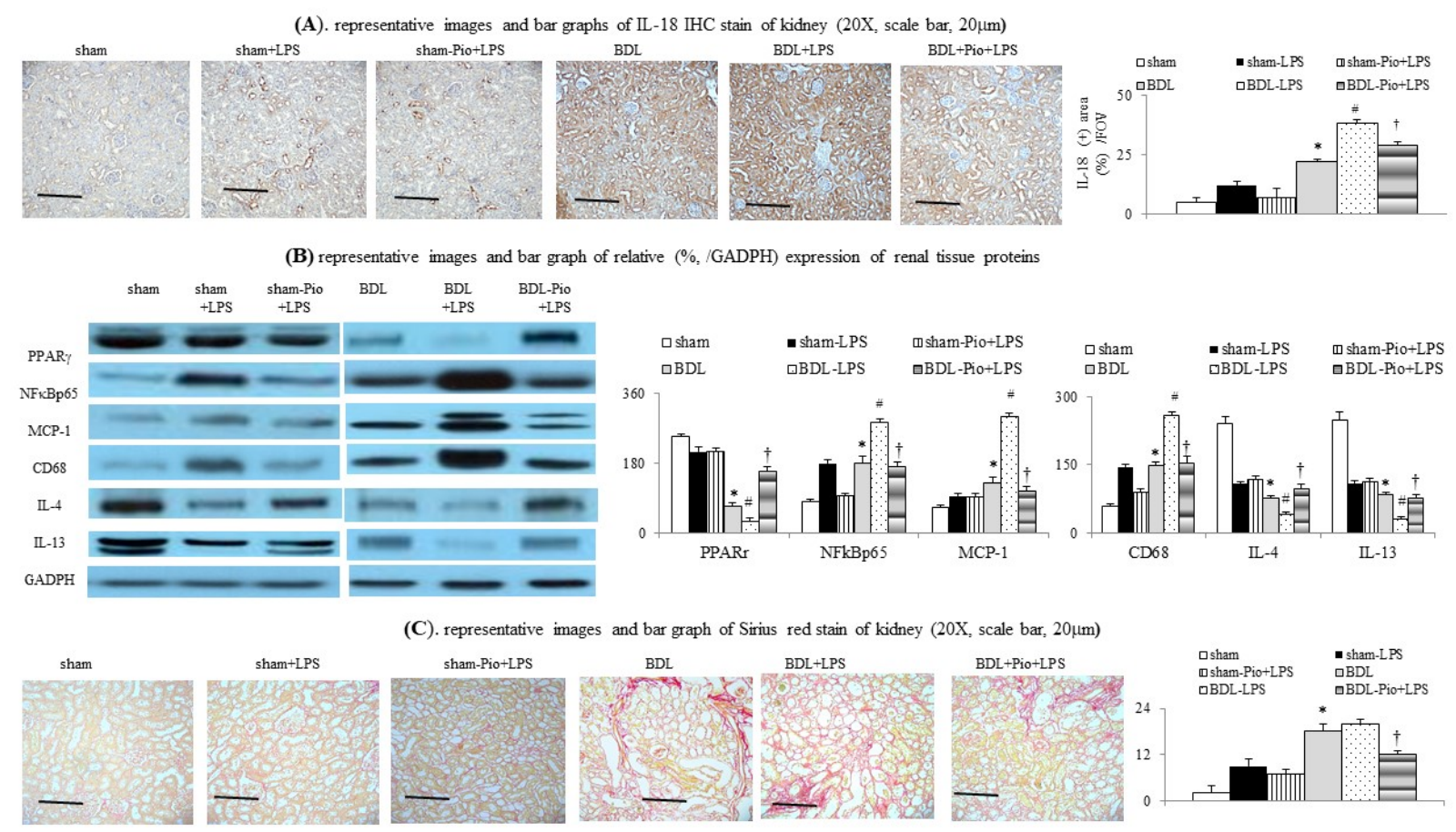

Figure 2. Chronic pioglitazone treatment suppressed LPS-induced acute on chronic renal dysfunction by prevention of increased renal macrophage infiltration. (A) Renal interleukin-18 (IL-18) expression; (B) various renal protein expressions between groups; (C) renal Sirius Red staining expression; ${ }^{*} p<0.05$ vs. sham group; $\# p<0.05$ vs. BDL group; $+p<0.05$ vs. BDL-LPS.

3.2. Chronic Pioglitazone Treatment Suppressed Serum Endotoxin, TNF, IL-6, ALT and Total Bilirubin in Advanced Cirrhotic Rats

Notably, cirrhotic rats were characterized by higher circulating TNF $\alpha$, IL-6, VCAM-1, ICMA-1, ALT, total bilirubin (TB) and lower serum albumin than rats in the sham group (Table 3 and Figure 1E,F). Acute LPS administration significantly increased circulating TNF $\alpha$, IL-6, VCAM-1, ICAM-1, ALT, TB and decreased serum albumin levels in the BDL+LPS group. In particular, the chronic pioglitazone pre-treatment prevented the LPS-induced increase in serum TNF $\alpha$, IL-6, VCAM-1, ICAM-1, ALT, TB and decreased serum albumin in BDL-Pio+LPS rats. The fasting blood sugar (FBS) level was slightly higher in the BDL group than in the sham group. Nonetheless, FBS was not affected by acute LPS administration and chronic pioglitazone treatment in sham-LPS, sham-Pio+LPS, BDL-LPS, and BDL-Pio+LPS rats.

3.3. Acute LPS Administration Downregulated Renal PPAR $\gamma$ Expression and Increased Renal M1 Macrophage Infiltration and Inflammation in Cirrhotic Ascitic Rats

In comparison with the sham group, the downregulation of renal PPAR $\gamma$ expression was accompanied by the upregulation of renal TNF $\alpha$, NFKBp65, IL-6 and increased renal macrophage infiltration (upregulated macrophage marker CD68) in the BDL group (Figures 1H,I and 2B,C). In the BDL group, the frequency of renal M1 macrophage infiltration (increased levels of TNF $\alpha$ and MCP-1 in cell lysates) was higher than that in the sham group (Figures 1H, 3A-D and 4A). The decrease in the percentage of renal M2 macrophages was companied by decreased levels of M2 marker (IL-4 and IL-13) in cell lysates of renal tissue of the BDL group (Figures 2B and 3C,D). Particularly, acute LPS administration induced a further increase in renal M1 macrophage infiltration, suppression of renal PPAR $\gamma$, and upregulation of renal TNF $\alpha, \mathrm{NF} \kappa \mathrm{Bp} 65$, IL-6 and MCP-1. Chronic pioglitazone pretreatment attenuated the above-mentioned LPS-related infiltrated macrophage-mediated pathogenic changes in the BDL group (Figures 1-3). 


\subsection{Effects of Chronic Pioglitazone Pre-Treatment Suppressed LPS-Induced TNFa-Mediated Renal Injury and Fibrosis in Cirrhotic Ascitic Rats}

Pioglitazone pre-treatment attenuated LPS-induced renal tubular injury (IL-18, Figure 2A), inflammation (TNF $\alpha$, IL-6, MCP-1, Figures 1G-I, 2B, 3B and 4A), tubulointerstitial injury and fibrosis (PAS-stained and Sirius Red-stained data, Figures 2C and 3A) by activating renal PPAR $\gamma$ expression. In addition, pioglitazone reduced the mortality rate of BDL rats to $32.9 \%$ during the $3 \mathrm{~h}$ following LPS injection compared with the saline treated group $(p<0.05)$.

Table 3. Clinical and serum biochemical data of rats with biliary cirrhosis receiving pioglitazone or vehicle.

\begin{tabular}{|c|c|c|c|c|c|c|}
\hline & $\begin{array}{l}\text { Sham } \\
(n=4)\end{array}$ & $\begin{array}{c}\text { Sham+LPS }(n=4) \\
\text { (Mean \% Increase from } \\
\text { Data of Sham Group) }\end{array}$ & $\begin{array}{l}\text { Sham-Pio+LPS }(n=4) \\
\text { (Mean \% Increase from } \\
\text { Data of Sham Group) }\end{array}$ & $\operatorname{BDL}(n=9)$ & $\begin{array}{c}\text { BDL+LPS }(n=9) \\
\text { (Mean \% Increase from } \\
\text { Data of Sham Group) }\end{array}$ & $\begin{array}{l}\text { BDL-Pio+LPS }(n=9) \\
\text { (Mean \% Increase from } \\
\text { Data of Sham Group) }\end{array}$ \\
\hline (Endotoxin) (pg/mL) & $7.3 \pm 0.9$ & $9.6 \pm 0.8$ & $8.3 \pm 0.5$ & $17.9 \pm 2.6^{*}$ & $27.3 \pm 2.8^{\# \#}$ & $19.4 \pm 1.8^{\ddagger}$ \\
\hline$(\mathrm{TNF} \alpha)(\mathrm{pg} / \mathrm{mL})$ & $12.9 \pm 5.4$ & $34.8 \pm 4.8$ & $17.1 \pm 2.8$ & $56.9 \pm 8.1^{*}$ & $168.3 \pm 9.6^{\# \#}$ & $64.1 \pm 7.1^{\ddagger}$ \\
\hline$(\mathrm{IL}-6)(\mathrm{pg} / \mathrm{mL})$ & $10.5 \pm 1.1$ & $17.6 \pm 2.1$ & $14.2 \pm 1.6$ & $29.8 \pm 3.4^{*}$ & $73.6 \pm 1.9^{\# \#}$ & $31.8 \pm 2.2$ 拉 \\
\hline $\begin{array}{l}\text { Fasting blood sugar } \\
\qquad(\mathrm{mg} / \mathrm{dL})\end{array}$ & $95 \pm 15$ & $108 \pm 20$ & $98 \pm 16$ & $112 \pm 23$ & $123 \pm 19$ & $119 \pm 16$ \\
\hline (Albumin) (g/L) & $4.1 \pm 0.7$ & $3.7 \pm 0.9$ & $3.9 \pm 0.8$ & $2.9 \pm 0.9$ & $2.6 \pm 0.4$ & $2.8 \pm 0.7$ \\
\hline$(\mathrm{ALT})(\mathrm{IU} / \mathrm{L})$ & $58 \pm 14$ & $69 \pm 13$ & $61 \pm 12$ & $98 \pm 7^{*}$ & 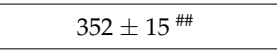 & $168 \pm 12$ 㧊 \\
\hline $\begin{array}{c}\text { (Total bilirubin) } \\
(\mathrm{mg} / \mathrm{dL})\end{array}$ & $0.38 \pm 0.09$ & $0.58 \pm 0.04$ & $0.41 \pm 0.06$ & $7.8 \pm 0.8^{*}$ & $18.5 \pm 1.7^{\# \#}$ & $13.1 \pm 2.5^{\ddagger}$ \\
\hline
\end{tabular}

In sham-LPS or BDL-LPS groups, blood was collected for various measurement $3 \mathrm{~h}$ after LPS infusion; ${ }^{*} p<0.05$ vs. sham group; ${ }^{\# \#} p<0.001$ vs. BDL group; $\ddagger$, $\ddagger \ddagger p<0.05,0.001$ vs. BDL+LPS group; TNF $\alpha$ : tumor necrosis factor $\alpha$ (TNF $\alpha)$; IL-6: interleukin-6; ALT: alanine aminotransferase.

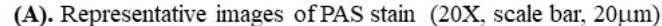
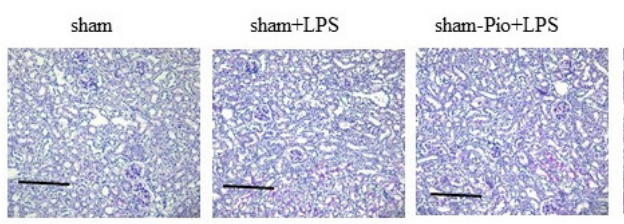

BDL
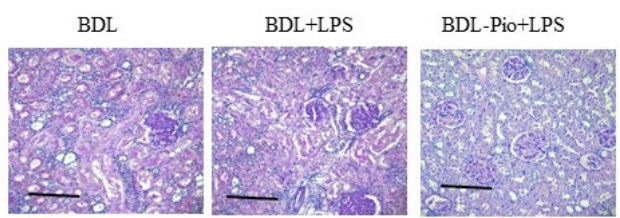

(C). Representative images and bar graphs of No. of M1/M2 macrophages in renal tissue
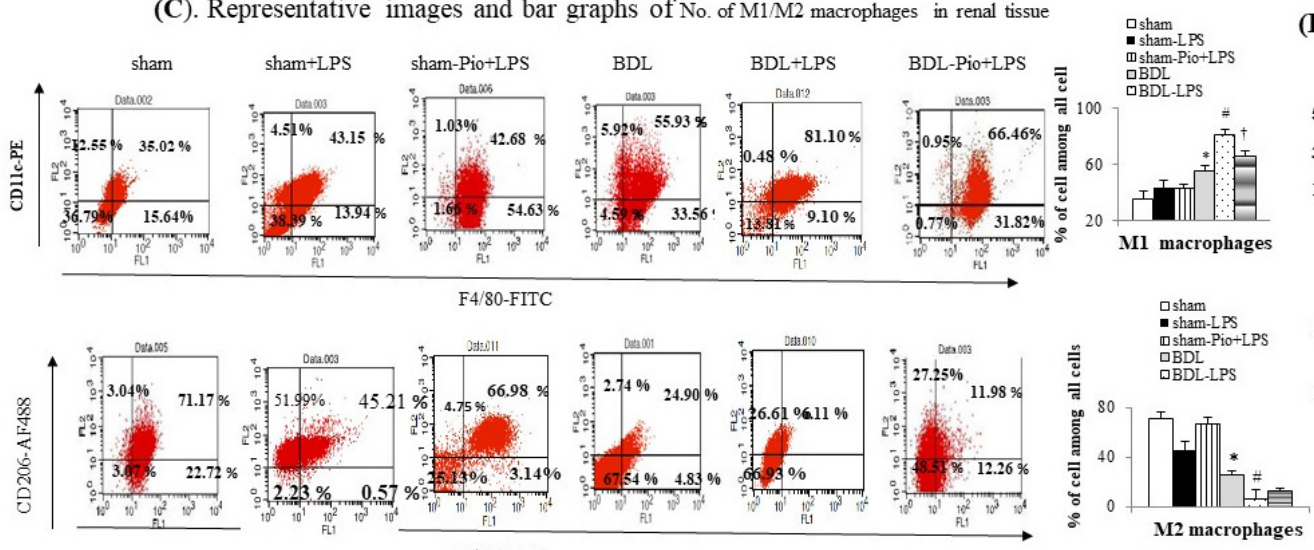

(D). $\mathrm{M} 1$ and $\mathrm{M} 2$ markers $m R N A$ expression in renal tissue( $\%$ to $18 \mathrm{~S})$
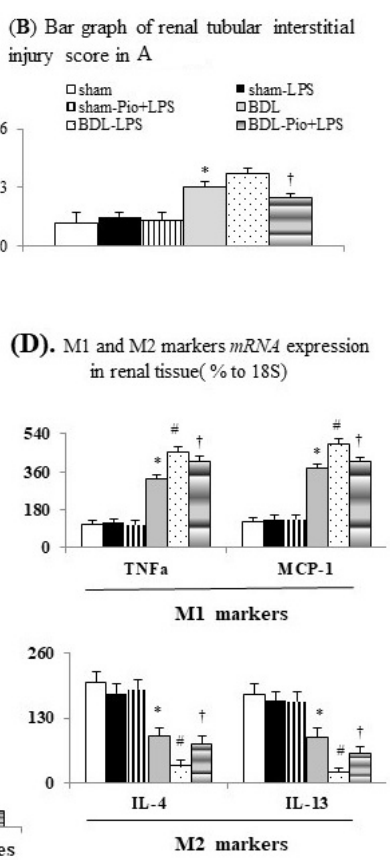

Figure 3. Chronic pioglitazone treatment suppressed the lipopolysaccharide (LPS)-induced acute on chronic renal injury by the prevention of increased renal M1 macrophages. (A,B) Renal PAS stain; (C) frequency of M1/M2 macrophages in renal tissue; (D). mRNA of M1/M2 markers in homogenates of renal tissue. ${ }^{*} p<0.05$ vs. sham group; $\#<<0.05$ vs. BDL group; $+p<0.05$ vs. BDL-LPS. 
(A). Representative images and bar graphs of MCP-1 IF stain of kidney (20X, scale bar, 20 $\mu \mathrm{m})$
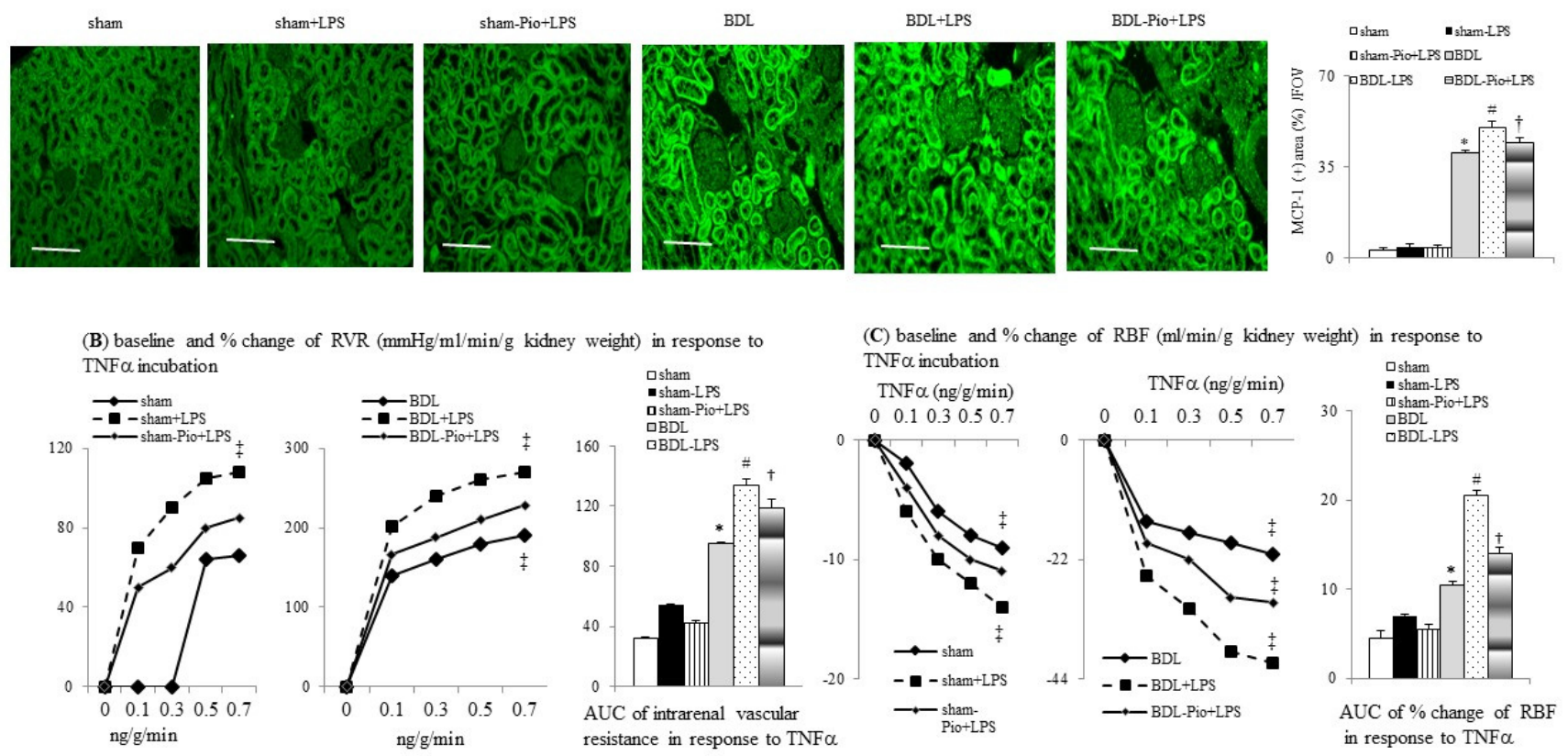

Figure 4. Chronic pioglitazone treatment inhibited the lipopolysaccharide (LPS)-enhanced TNF $\alpha$ and tumor necrosis factor $\alpha(\mathrm{TNF} \alpha)$-induced increase in renal vascular resistance (RVR) of BDL-cirrhotic rats. (A) Immunofluorescence (IF) stain of monocyte chemoattractant protein-1 (MCP-1) expression in rat kidney. Concentration-response curve and bar graphs of AUC of (B) RVR and (C) renal blood flow (RABF) in response to cumulative concentrations of TNF $\alpha$; $p<0.05 \mathrm{vs.} \mathrm{sham}$ group; $\# p<0.05$ vs. BDL group; $\uparrow p<0.05$ vs. BDL-LPS; $\ddagger p<0.05$ vs. lower concentration of TNF $\alpha$.

\subsection{Chronic PPAR $\gamma$ Agonist Pioglitazone Pre-Treatment Attenuates the LPS-Induced} TNF $\alpha$-Mediated Increase in Renal Vascular Resistance (RVR) in Cirrhotic Ascitic Rats

Figure $4 \mathrm{~B}, \mathrm{C}$ shows that the cumulative concentrations of TNF $\alpha$ induced an increase in RVR and a decrease in RABF in sham-perfused kidneys. Significantly, the degrees of TNF $\alpha$ induced increase in RVR and decrease in RABF were higher in BDL-perfused rat kidneys than those in sham-perfused kidney. Furthermore, acute LPS administration significantly increased the magnitude of the TNF $\alpha$-induced increase in RVR and the decrease in RABF both in sham+LPS and BDL+LPS groups, whereas the degree of changes was higher in the BDL+LPS group than those in the sham+LPS group. In BDL rats with chronic pioglitazone pre-treatment, a lower degree of LPS-enhanced TNF $\alpha$-induced increase in RVR and decrease in RABF were noted in the BDL-Pio+LPS group than in the BDL+LPS group (Figure 4B,C).

\subsection{Chronic Pioglitazone Pre-Treatment Attenuated LPS-Induced TNF $\alpha / N F \kappa B-M e d i a t e d ~ R e n a l$} Tissue and Renal Vascular Inflammation in BDL Rats

In comparison with the sham group, lower PPAR $\gamma$ expression was associated with increased levels of inflammatory mediators (TNF $\alpha$, IL-6, MCP-1, NFkBp65, and CD68, Figure $5 \mathrm{~A}, \mathrm{~B}, \mathrm{E}, \mathrm{H})$ in the renal arterial tissue of the BDL group. Furthermore, acute LPS preadministration significantly downregulated PPAR $\gamma$ expression, increased M1 macrophage infiltration, and increased vascular inflammation in renal arteries of the BDL+LPS group. In particular, chronic pioglitazone pre-treatment attenuated the LPS-induced TNF $\alpha / N F \kappa B-$ mediated pathogenic changes in the renal arterial tissue of the BDL-Pio+LPS group. 

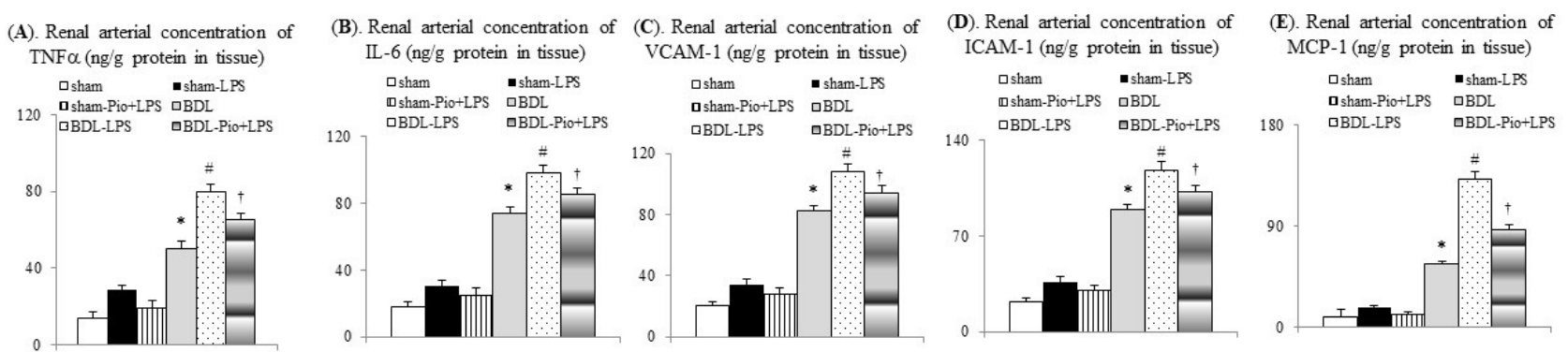

(H). Representative image and bar graph of relative $(\%, / \mathrm{GADPH})$ expression of various renal arterial
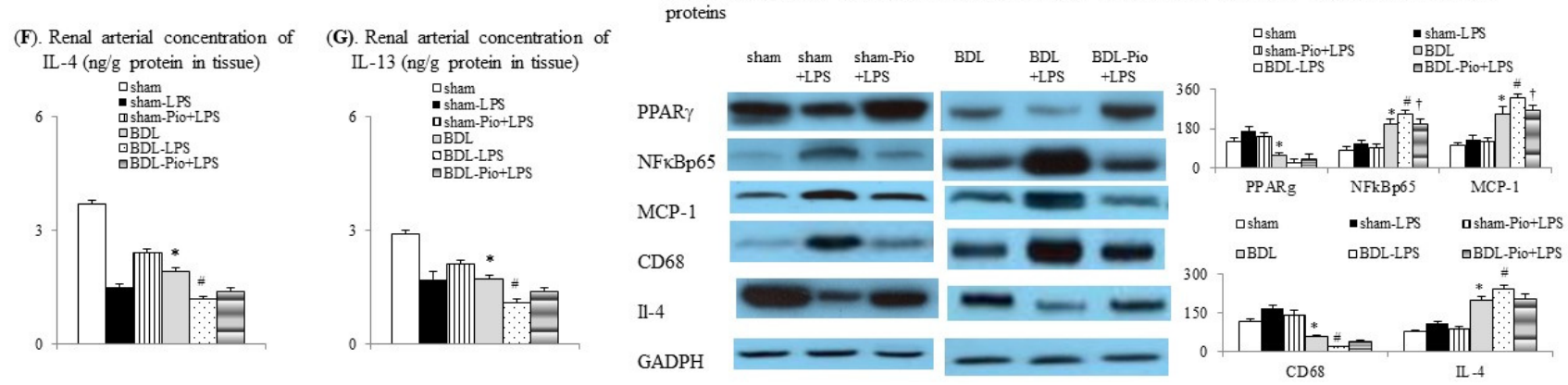

Figure 5. Chronic pioglitazone treatment inhibited the lipopolysaccharide (LPS)-induced vascular inflammation in rat cirrhotic renal arteries. Renal arterial concentrations of (A) TNF $\alpha$, tumor necrosis factor $\alpha(\mathrm{TNF} \alpha)$, (B) interleukin-6 (IL-6), (C) vascular cell adhesion molecule-1(VCAM-1), (D) intracellular adhesion molecule-1 (ICAM-1), (E) monocyte chemoattractant protein-1 (MCP-1), (F) interleukin-4 (IL-4), and (G) interleukin-13 (IL-13). (H) Expression of various proteins in renal arteries. ${ }^{*} p<0.05$ vs. sham group; $\# p<0.05$ vs. BDL group; $+p<0.05$ vs. BDL-LPS.

\section{Discussion}

In this study, cirrhotic portal hypertensive rats were characterized by reduced RABF, increased RVR, upregulated renal inflammatory/adhesion molecules markers, and progressive renal dysfunction. In particular, acute endotoxin (LPS) administration induced acute on chronic renal dysfunction by increasing $\mathrm{TNF} \alpha-\mathrm{NF} \kappa \mathrm{B}$-mediated renal inflammatory markers. Chronic pioglitazone pre-treatment prevented LPS-induced renal pathogenic changes in the cirrhotic group. Activation of systemic, renal tissue and renal vessel levels of PPAR $\gamma$ by chronic pioglitazone treatment has beneficial effects on the endotoxemia-related $\mathrm{TNF} \alpha / \mathrm{NF} \mathrm{BB}$-mediated acute on chronic renal inflammation in cirrhosis. This study revealed that normalization of renal and renal arterial levels of PPAR $\gamma$ effectively prevented LPS-induced acute and chronic renal dysfunction in cirrhotic ascitic rats.

Cirrhotic mice are suspected to develop LPS-induced TNF $\alpha$-mediated AKI [27]. In cirrhotic patients with spontaneous bacterial peritonitis (SBP), those with renal impairment had significantly higher plasma and ascitic fluid TNF $\alpha$ levels than those without renal dysfunction [28]. In this study, the chronic inhibition of the levels of circulating, renal tissue and renal arterial TNF $\alpha$ by the chronic PPAR $\gamma$ agonist pioglitazone significantly improved renal function of cirrhotic ascitic rats (Figure 6).

TNF $\alpha$ directly induces lipocalin-2 and IL-18 production from renal epithelial cells, which are markers that represent the severity of renal injury [29-32]. In the Child-Pugh class of decompensated cirrhosis, urinary lipocalin-2/IL-18 levels increased and GFR decreased significantly [30-32]. The most common cause for acute on chronic renal dysfunction in cirrhosis is acute tubular necrosis (ATN), which occurs as a complication of sepsis $[4,5,9,15,32]$. Urine levels of IL-18 and lipocalin-2 from patients with cirrhosis discriminate between those with ATN and other types of kidney impairments [32]. Activation of renal PPAR- $\gamma$ with pioglitazone suppressed renal IL-18 and lipocalin-2 expression in a renal ischemia-reperfusion model [33]. In our study, restoration of renal tissue PPAR $\gamma$ levels by chronic pioglitazone treatment suppressed the progressive 
TNF $\alpha$-mediated increased RVR and renal injury (inhibition of urinary lipocalin-2 and IL-18) in cirrhotic ascitic rats with renal dysfunction. As shown in Table 2, in comparison with the BDL group, the acute intraperitoneal (IP) infusion of LPS induced a mean $195 \%(56.9 \pm 8.1$ vs. $168.3 \pm 9.6 \mathrm{pg} / \mathrm{mL})$ increase in serum TNF $\alpha$ level in the BDL+LPS group, whereas LPS only induced a $12 \%(56.9 \pm 8.1 \mathrm{vs.} 64.1 \pm 7.1 \mathrm{pg} / \mathrm{mL})$ increase in serum TNF $\alpha$ level in the BDL-pio+LPS group. This result indicated that pioglitazone treatment prevented $183 \%$ of the LPS-induced elevation of serum TNF $\alpha$ level in cirrhotic rats. Additionally, in comparison with liver injury markers (serum ALT level) of the BDL group, the $259 \%$ of elevation of liver injury markers in the BDL+LPS group was suppressed to $71 \%$, which indicated that the pioglitazone treatment prevented $186 \%$ of the LPS-induced elevation of serum ALT (Table 2). Similarly, the pioglitazone treatment suppressed $40 \%$ of the LPS-elevated renal injury marker (renal IL-18 expression) in the BDL-pio+LPS group. Particularly, a higher degree of pioglitazone-suppressed liver injury marker (serum ALT) than renal marker (IL-18) might be the result of the direct access of LPS to the portal system by IP administration. These results indicated that the circulating TNF $\alpha$ mediated the LPS-induced liver and renal injury, and these changes in cirrhotic rats in this study can be ameliorated by pioglitazone treatment.

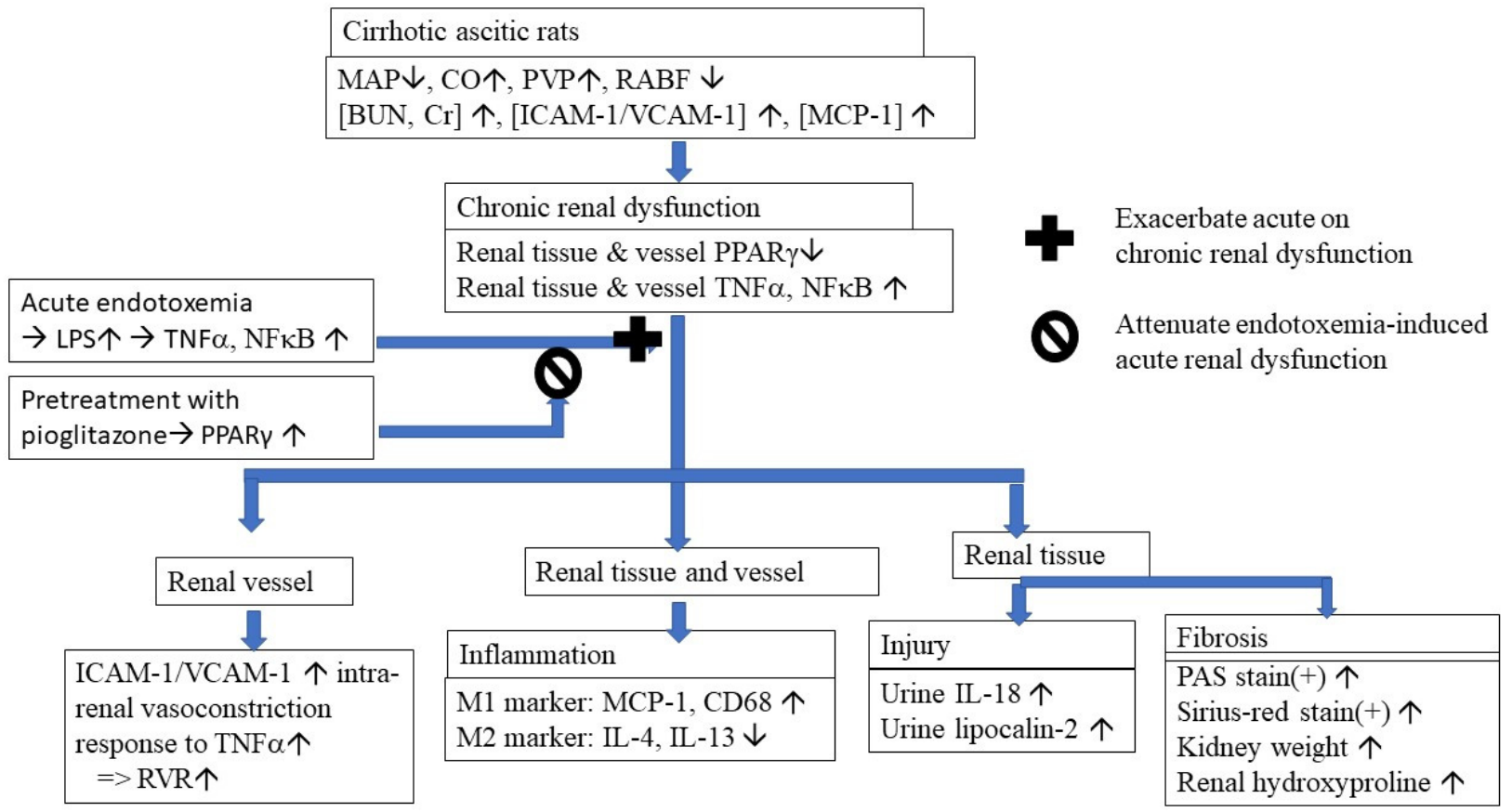

Figure 6. Graphical summary of the pathogenic mechanisms and effects of restoration of renal tissue and vessels PPAR with pioglitazone on the endotoxemia-induced acute on chronic renal dysfunction in cirrhotic rats. MAP: mean arterial pressure; CO: cardiac output; PVP: portal venous pressure; RABF: renal arterial blood flow; ICAM-1: intercellular adhesion molecule 1; VCAM-1: vascular cell adhesion molecule 1; MCP-1: monocyte chemoattractant protein 1; PPAR $\gamma$ : peroxisome proliferator-activated receptor gamma; TNF $\alpha$ : tumor necrosis factor alpha; NFkB: nuclear factor kappa-light-chain-enhancer of activated B cells; LPS: lipopolysaccharide; RVR: renal vascular resistance; M1/M2: two types of macrophages; PAS stain: periodic acid-Schiff stain.

$\mathrm{NFKB}$ plays a major role in the inflammatory response, and over-activation of $\mathrm{NF} \kappa \mathrm{B}$ induces the overexpression of $\mathrm{TNF} \alpha$, thus accelerating renal injury $[4,7,8,13,34]$. In streptozotocin-induced diabetic nephropathy rats, chronic pioglitazone treatment reduced renal NFKB, IL-1 $\beta$ and IL-18 levels, depressed the glomerular mesangial expansion, and decreased serum BUN/creatinine [35].

Intercellular adhesion molecule-1 (ICAM-1) and vascular cell adhesion molecule-1 (VCAM-1) expressed on endothelial cells are involved in the interaction between leukocytes and endothelial cells $[6,36]$. Suppression of $N F \kappa B$ signaling inhibits $\mathrm{TNF} \alpha$-stimulated 
expression of ICAM- 1 and VCAM- 1 and the adhesion of monocytes to the human bronchial epithelial cell line [36]. In cholestasis, TNF $\alpha$ mediates IL-6 release from macrophages to aggravate renal dysfunction $[7,9,10]$. In a sepsis model, pioglitazone reduced LPS-induced TNF $\alpha$ and IL-6 production from mouse macrophages through inhibition of NFKB [37,38]. Pioglitazone was found to inhibit TNF $\alpha$-induced expression of ICAM- 1 and VCAM- 1 in activated cultured endothelial cells and an ischemia/reperfusion renal injury model $[33,39]$. Notably, in cirrhotic ascitic rats from our study, chronic pioglitazone pre-treatment attenuated LPS-induced TNF $\alpha / \mathrm{NFKB}$-mediated acute on chronic renal dysfunction by suppressing renal IL-6, ICAM-1 and VCAM-1.

LPS can induce NFkB-mediated MCP-1 production in rat macrophages and renal tubular epithelial cells [40,41]. MCP-1 can stimulate glomerular macrophage infiltration and renal inflammation [42,43]. Increased renal macrophage infiltration is associated with progressive tubulointerstitial renal fibrosis in mice three weeks after BDL [44]. Cirrhotic patients with higher urine MCP-1 level have a higher probability of developing acute renal dysfunction [45]. Chronic pioglitazone protects patients from diabetic nephropathy by reducing urinary MCP-1 excretion and proteinuria [46]. In our current study, pioglitazone pre-treatment prevented LPSinduced acute on chronic renal dysfunction by inhibiting MCP-1-mediated renal macrophage infiltration and renal inflammation in cirrhotic ascitic rats.

M1 macrophages exert a pathogenic function in renal inflammation, whereas M2 macrophages appear to suppress inflammation and promote injury repair [47]. Increased M1 macrophage infiltration is a critical pathogenic factor for the initiation of LPS-induced or inflammation-driven renal dysfunction [48,49]. Activation of PPAR $\gamma$ with pioglitazone suppresses M1 macrophage polarization and skews circulating monocytes toward an anti-inflammatory M2 macrophage phenotype $[19,20]$. The CD68 molecule, which is highly expressed on tissue macrophages, is functionally important for M1 macrophages. Treatment with pioglitazone reduces $\mathrm{CD}^{+} 8^{+}$macrophage infiltration and MCP-1 release in adipose tissue [50]. In summary, chronic pioglitazone pre-treatment in cirrhotic ascitic rats effectively decreased LPS-induced M1 polarization of macrophages and renal dysfunction.

It has been reported that intraperitoneal (IP) administration of drugs in experimental animals is a justifiable route for pharmacological and proof-of-concept studies where the goal is to evaluate the effect(s) of target engagement rather than the properties of a drug formulation and/or its pharmacokinetics for clinical translation. A previous study had reported that the bioavailability and absorption for the IP route of small molecular agents (MW < 5000), such as pioglitazone (MW 392.9), are higher than those by oral route. However, both IP and oral routes have a similar degree of first pass metabolism of these small molecular agents in the liver [51]. In comparison with the oral route, the IP technique is easy to master and minimally stressful for animals. The IP route is especially commonly used in chronic studies involving rats for which repetitive oral access is challenging. In this study, two weeks of pioglitazone was administered by IP with an azert osmotic pump. Pioglitazone is well absorbed, has an oral bioavailability of about $80 \%$, and is extensively metabolized to active and inactive metabolites in the liver [52-55]. In future studies, the effectiveness of oral administration of two weeks of pioglitazone is needed to be compared with the IP administration in this study.

A high prevalence of renal dysfunction has been reported among non-alcoholic steatohepatitis (NASH) patients [56]. Severe NASH is the most rapidly growing indication for simultaneous liver-kidney transplantation, with poor renal outcomes [57]. Several largescale randomized controlled trials have reported the effectiveness of pioglitazone in treating NASH to improve markers of hepatic steatosis and fibrosis on liver histology $[52,58]$. A recent study reported that a low dose of pioglitazone was safe and effective in diabetes patients with CKD [53]. In particular, pioglitazone decreases the incidence of new-onset end-stage renal disease in diabetes patients [59]. Renal dysfunction in NASH and diabetic patients share a common pathogenesis $[60,61]$. Taken together, pioglitazone might have the potential to protect NASH patients from the development of renal dysfunction; this needs to be evaluated in future studies. 


\section{Conclusions}

In conclusion, as shown in Figure 6, restoration of systemic, renal tissue and renal arterial PPAR $\gamma$ by chronic pioglitazone treatment attenuated cirrhosis-related renal dysfunction and endotoxemia-induced acute on chronic renal dysfunction.

Author Contributions: Methodology, S.-Y.L., C.-C.H. and Y.-Y.Y.; investigation, T.-L.L., N.-R.K. and S.-F.H.; resources, T.-H.L.; writing—original draft preparation, S.-Y.L., Y.-Y.Y., and H.-C.L.; writingreview and editing S.-Y.L., Y.-Y.Y. and H.-C.L.; supervision, M.-C.H.; funding acquisition, C.-W.L. All authors have read and agreed to the published version of the manuscript.

Funding: This work was supported in part by the Ministry of Science and Technology of the Republic of China: MOST 414 109-2314-B-010-032-MY3, MOST 109-2511-H-075 -001 -MY2 and MOST-110-2511-H-A491-504-MY3; Grant No. PED1090388 from Ministry of Education, Grant No. V110C-033 (Taipei Veterans General 416 Hospital) and grant No. 107F M01-0603 from National Yang-Ming Chiao Tung University.

Institutional Review Board Statement: This study was approved by the Animal Experiments Committee of Yang-Ming Chiao Tung University and was performed according to the "Guide for the care and use of laboratory animals" prepared by the National Academy of Science, USA and the ARRIVE guidelines with the permission number of IACUC 1080403.

Data Availability Statement: The datasets in this study are available from the corresponding author upon reasonable request.

Acknowledgments: We are grateful to Che-Jui Chang, Chuan-Ju Lin, Hsu-Shan Hung and Yu-Chieh $\mathrm{Wu}$, who were in charge of all experiments.

Conflicts of Interest: The authors declare no conflict of interest. The funder had no role in the design of the study; in the collection, analyses, or interpretation of data; in the writing of the manuscript, or in the decision to publish the results.

\section{References}

1. McAvoy, N.C.; Semple, S.; Richards, J.M.J.; Robson, A.J.; Patel, D.; Jardine, A.G.M.; Leyland, K.; Cooper, A.S.; Newby, D.E.; Hayes, P.C. Differential visceral blood flow in the hyperdynamic circulation of patients with liver cirrhosis. Aliment. Pharmacol. Ther. 2016, 43, 947-954. [CrossRef] [PubMed]

2. $\quad$ Lin, H.C.; Yang, Y.Y.; Tsai, T.H.; Huang, C.M.; Huang, Y.T.; Lee, F.Y.; Liu, T.T.; Lee, S.D. The relationship between endotoxemia and hepatic endocannabinoids in cirrhotic rats with portal hypertension. J. Hepatol. 2011, 54, 1145-1153. [CrossRef] [PubMed]

3. Trebicka, J.; Krag, A.; Gansweid, S.; Appenrodt, B.; Schiedermaier, P.; Sauerbruch, T.; Spengler, U. Endotoxin and tumor necrosis factor-receptor levels in portal and hepatic vein of patients with alcoholic liver cirrhosis receiving elective transjugular intrahepatic portosystemic shunt. Eur. J. Gastroenterol. Hepatol. 2011, 23, 1218-1225. [CrossRef]

4. Peng, J.L.; Techasatian, W.; Hato, T.; Liangpunsakul, S. Role of endotoxemia in causing renal dysfunction in cirrhosis. Investig. Med. 2020, 68, 26-29. [CrossRef]

5. Nakatani, Y.; Fukui, H.; Kitano, H.; Nagamoto, I.; Tsujimoto, T.; Kuriyama, S.; Kikuchi, E.; Hoppou, K.; Tsujii, T. Endotoxin clearance and its relation to hepatic and renal disturbances in rats with liver cirrhosis. Liver Int. 2001, 21, 64-70. [CrossRef]

6. Sole, C.; Sola, E.; Morales-Ruiz, M.; Huelin, P.; Carol, M.; Moreira, R.; Graupera, I.; Pose, E.; Napoleone, L.; De Prada, G.; et al. Characterization of systemic inflammatory response in hepatorenal syndrome in cirrhosis. A major role for il-6, TNF-alpha, and VCAM. J. Hepatol. 2018, 68, 698. [CrossRef]

7. Hu, Z.H.; Kong, Y.Y.; Ren, J.J.; Huang, T.J.; Wang, Y.Q.; Liu, L.X. Kidney and lung tissue modifications after BDL-induced liver injury in mice are associated with increased expression of IGFBPrP1 and activation of the NF- $\mathrm{KB}$ inflammation pathway. Int. J. Clin. Exp. Pathol. 2020, 13, 192.

8. Van Lambalgen, A.A.; Van Kraats, A.A.; Van den Bos, G.C.; Stel, H.V.; Straub, J.; Donker, A.J.; Thijs, L.G. Renal function and metabolism during endotoxemia in rats: Role of hypoperfusion. Circ. Shock 1991, 35, 164-173.

9. Huang, L.T.; Hung, J.F.; Chen, C.C.; Hsieh, C.S.; Yu, H.R.; Hsu, C.N.; Tain, Y.L. Endotoxemia exacerbates kidney injury and increases asymmetric dimethylarginine in young bile duct-ligated rats. Shock 2012, 37, 441-448. [CrossRef]

10. Chou, Y.T.; Liu, T.T.; Yang, U.C.; Huang, C.C.; Liu, C.W.; Huang, S.F.; Li, T.H.; Liu, H.M.; Lin, M.W.; Yang, Y.Y.; et al. Intestinal SIRT1 Deficiency-Related Intestinal Inflammation and Dysbiosis Aggravate TNF $\alpha$-Mediated Renal Dysfunction in Cirrhotic Ascitic Mice. Int. J. Mol. Sci. 2021, 22, 1233. [CrossRef]

11. Majid, D.S. Tumor necrosis factor- $\alpha$ and kidney function: Experimental findings in mice. Adv. Exp. Med. Biol. 2011, 691, 471-480. 
12. Shahid, M.; Francis, J.; Majid, D.S. Tumor necrosis factor- $\alpha$ induces renal vasoconstriction as well as natriuresis in mice. Am. J. Physiol. 2008, 295, 1836-1844. [CrossRef]

13. Kalambokis, G.N.; Mouzaki, A.; Rodi, M.; Pappas, K.; Fotopoulos, A.; Xourgia, X.; Tsianos, E.V. Rifaximin improves systemic hemodynamics and renal function in patients with alcohol-related cirrhosis and ascites. Clin. Gastroenterol. Hepatol. 2012, 10, 815-818. [CrossRef]

14. Corrales, P.; Izquierdo-Lahuerta, A.; Medina-Gómez, G. Maintenance of kidney metabolic homeostasis by PPAR gamma. Int. J. Mol. Sci. 2018, 19, 2063. [CrossRef]

15. Rodriguez, W.E.; Tyagi, N.; Joshua, I.G.; Passmore, J.C.; Fleming, J.T.; Falcone, J.C.; Tyagi, S.C. Pioglitazone mitigates renal glomerular vascular changes in high-fat, high-calorie-induced type 2 diabetes mellitus. Am. J. Physiol. Renal Physiol. 2006, 291, 694-701. [CrossRef] [PubMed]

16. Liu, D.; Xiong Zeng, B.; Shang, Y. Decreased Expression of Peroxisome Proliferator-Activated Receptor $\gamma$ in Endotoxin-Induced Acute Lung Injury. Physiol. Res. 2006, 55, 291-299.

17. Collin, M.; Patel, N.S.; Dugo, L.; Thiemermann, C. Role of peroxisome proliferator-activated receptor- $\gamma$ in the protection afforded by 15 -deoxy $\Delta 12,14$ prostaglandin J2 against the multiple organ failure caused by endotoxin. Crit. Care Med. 2004, 32, 826-831. [CrossRef]

18. Lee, S.; Kim, W.; Kang, K.P.; Moon, S.O.; Sung, M.J.; Kim, D.H.; Kim, H.J.; Park, S.K. Agonist of peroxisome proliferator-activated receptor- $\gamma$, rosiglitazone, reduces renal injury and dysfunction in a murine sepsis model. Nephrol. Dial. Transplant. 2005, 20, 1057-1065. [CrossRef]

19. Chen, Z.; Yuan, P.; Sun, X.; Tang, K.; Liu, H.; Han, S.; Ye, T.; Liu, X.; Yang, X.; Zeng, J.; et al. Pioglitazone decreased renal calcium oxalate crystal formation by suppressing M1 macrophage polarization via the PPAR- $\gamma-m i R-23$ axis. Am. J. Physiol. Renal Physiol. 2019, 317, 137-151. [CrossRef]

20. Zhang, C.; Zhang, Y.; Zhang, C.; Liu, Y.; Liu, Y.; Xu, G. Pioglitazone increases VEGFR3 expression and promotes activation of M2 macrophages via the peroxisome proliferator-activated receptor $\gamma$. Mol. Med. Rep. 2019, 19, 2740-2748. [CrossRef]

21. Wang, N.; Symons, J.D.; Zhang, H.; Jia, Z.; Gonzalez, F.J.; Yang, T. Distinct functions of vascular endothelial and smooth muscle PPAR $\gamma$ in regulation of blood pressure and vascular tone. Toxicol. Pathol. 2009, 37, 21-27. [CrossRef]

22. Ji, Y.; Liu, J.; Wang, Z.; Li, Z. PPAR $\gamma$ agonist rosiglitazone ameliorates LPS-induced inflammation in vascular smooth muscle cells via the TLR4/TRIF/IRF3/IP-10 signaling pathway. Cytokine 2011, 55, 409-419. [CrossRef]

23. Lv, X.; Song, J.G.; Li, H.H.; Ao, J.P.; Zhang, P.; Li, Y.S.; Song, S.L.; Wang, X.R. Decreased hepatic peroxisome proliferator-activated receptor- $\gamma$ contributes to increased sensitivity to endotoxin in obstructive jaundice. World J. Gastroenterol. 2011, 17, 5267. [CrossRef]

24. Aghaei, I.; Shabani, M.; Doustar, N.; Nazeri, M.; Dehpour, A. Peroxisome proliferator-activated receptor- $\gamma$ activation attenuates motor and cognition impairments induced by bile duct ligation in a rat model of hepatic cirrhosis. Pharmacol. Biochem. Behav. 2014, 120, 133-139. [CrossRef]

25. Schwabl, P.; Payer, B.A.; Grahovac, J.; Klein, S.; Horvatits, T.; Mitterhauser, M.; Stift, J.; Boucher, Y.; Trebicka, J.; Trauner, M.; et al Pioglitazone decreases portosystemic shunting by modulating inflammation and angiogenesis in cirrhotic and non-cirrhotic portal hypertensive rats. J. Hepatol. 2014, 60, 1135-1142. [CrossRef]

26. Cheng, T.Y.; Lee, W.S.; Huang, H.C.; Lee, F.Y.; Chang, C.C.; Lin, H.C.; Lee, S.D. The effects of pioglitazone in cirrhotic rats with hepatopulmonary syndrome. J. Chin. Med. Assoc. 2017, 80, 683-689. [CrossRef]

27. Carl, D.E.; Ghosh, S.S.; Gehr, T.W.; Abbate, A.; Toldo, S.; Sanyal, A.J. A model of acute kidney injury in mice with cirrhosis and infection. Liver Int. 2016, 36, 865-873. [CrossRef]

28. Navasa, M.; Follo, A.; Filella, X.; Jiménez, W.; Francitorra, A.; Planas, R.; Rimola, A.; Arroyo, V.; Rodés, J. Tumor necrosis factor and interleukin-6 in spontaneous bacterial peritonitis in cirrhosis: Relationship with the development of renal impairment and mortality. Hepatology 1998, 27, 1227-1232. [CrossRef]

29. Hashikata, A.; Yamashita, A.; Suzuki, S.; Nagayasu, S.; Shinjo, T.; Taniguchi, A.; Fukushima, M.; Nakai, Y.; Nin, K.; Watanabe, N.; et al. The inflammation-lipocalin 2 axis may contribute to the development of chronic kidney disease. Nephrol. Dial. Transplant. 2014, 29, 611-618. [CrossRef]

30. Lei, L.; Li, L.P.; Zeng, Z.; Mu, J.X.; Yang, X.; Zhou, C.; Wang, Z.L.; Zhang, H. Value of urinary KIM-1 and NGAL combined with serum Cys C for predicting acute kidney injury secondary to decompensated cirrhosis. Sci. Rep. 2018, 8, 1-9. [CrossRef]

31. Allegretti, A.S.; Solà, E.; Ginès, P. Clinical application of kidney biomarkers in cirrhosis. Am. J. Kidney Dis. 2020, 76, 710-719. [CrossRef]

32. Puthumana, J.; Ariza, X.; Belcher, J.M.; Graupera, I.; Ginès, P.; Parikh, C.R. Urine interleukin 18 and lipocalin 2 are biomarkers of acute tubular necrosis in patients with cirrhosis: A systematic review and meta-analysis. Clin. Gastroenterol. Hepatol. 2017, 15, 1003-1013. [CrossRef]

33. Ragab, D.; Abdallah, D.M.; El-Abhar, H.S. Cilostazol renoprotective effect: Modulation of PPAR- $\gamma$, NGAL, KIM-1 and IL-18 underlies its novel effect in a model of ischemia-reperfusion. PLoS ONE 2014, 9, e95313. [CrossRef]

34. Padillo, F.J.; Cruz, A.; Segura-Jiménez, I.; Ruiz-Rabelo, J.; Vázquez-Ezquerra, M.R.; Perea-Alvarez, M.D.; Peña, J.; Briceño, J.; Muntané, J. Anti-TNF- $\alpha$ treatment and bile duct drainage restore cellular immunity and prevent tissue injury in experimental obstructive jaundice. Int. J. Immunopathol. Pharmacol. 2007, 20, 855-860. [CrossRef] 
35. Wang, Y.; Yu, B.; Wang, L.; Yang, M.; Xia, Z.; Wei, W.; Zhang, F.; Yuan, X. Pioglitazone ameliorates glomerular NLRP3 inflammasome activation in apolipoprotein E knockout mice with diabetes mellitus. PLoS ONE 2017, 12, e0181248. [CrossRef]

36. Jung, J.; Ko, S.H.; Yoo, D.Y.; Lee, J.Y.; Kim, Y.J.; Choi, S.M.; Kang, K.K.; Yoon, H.J.; Kim, H.; Youn, J.; et al. 5,7-Dihydroxy-3,4,6trimethoxyflavone inhibits intercellular adhesion molecule 1 and vascular cell adhesion molecule 1 via the A kt and nuclear factor- $\kappa$ B-dependent pathway, leading to suppression of adhesion of monocytes and eosinophils to bronchial epithelial cells. Immunology 2012, 137, 98-113.

37. Ao, C.; Huo, Y.; Qi, L.; Xiong, Z.; Xue, L.; Qi, Y. Pioglitazone suppresses the lipopolysaccharide-induced production of inflammatory factors in mouse macrophages by inactivating NF-кB. Cell Biol. Int. 2010, 34, 723-730. [CrossRef]

38. Kaplan, J.; Nowell, M.; Chima, R.; Zingarelli, B. Pioglitazone reduces inflammation through inhibition of NF- $\kappa B$ in polymicrobial sepsis. Innate Immun. 2014, 20, 519-528. [CrossRef] [PubMed]

39. Pasceri, V.; Wu, H.D.; Willerson, J.T.; Yeh, E.T. Modulation of vascular inflammation in vitro and in vivo by peroxisome proliferator-activated receptor- $\gamma$ activators. Circulation 2000, 101, 235-238. [CrossRef] [PubMed]

40. Wang, Y.; Rangan, G.K.; Goodwin, B.; Tay, Y.C.; Wang, Y.; Harris, D.C. Lipopolysaccharide-induced MCP-1 gene expression in rat tubular epithelial cells is nuclear factor-kB dependent. Kidney Int. 2000, 57, 2011-2022. [CrossRef]

41. Wang, X.; Jiang, X.; Deng, B.; Xiao, J.; Jin, J.; Huang, Z. Lipopolysaccharide and palmitic acid synergistically induced MCP-1 production via MAPK-meditated TLR4 signaling pathway in RAW264. 7 cells. Lipids Health Dis. 2019, 18, 1-9. [CrossRef]

42. Tang, W.W.; Qi, M.; Warren, J.S. Monocyte chemoattractant protein 1 mediates glomerular macrophage infiltration in anti-GBM $\mathrm{Ab}$ GN. Kidney Int. 1996, 50, 665-671. [CrossRef]

43. Tesch, G.H.; Schwarting, A.; Kinoshita, K.; Lan, H.Y.; Rollins, B.J.; Kelley, V.R. Monocyte chemoattractant protein-1 promotes macrophage-mediated tubular injury, but not glomerular injury, in nephrotoxic serum nephritis. J. Clin. Investig. 1999, 103, 73-80. [CrossRef]

44. Fickert, P.; Krones, E.; Pollheimer, M.J.; Thueringer, A.; Moustafa, T.; Silbert, D.; Halilbasic, E.; Yang, M.; Jaeschke, H.; Stokman, G.; et al. Bile acids trigger cholemic nephropathy in common bile-duct-ligated mice. Hepatology 2013, 58, 2056-2069. [CrossRef]

45. Graupera, I.; Sola, E.; Fabrellas, N.; Moreira, R.; Sole, C.; Huelin, P.; de la Prada, G.; Pose, E.; Ariza, X.; Risso, A.; et al. Urine monocyte chemoattractant protein-1 is an independent predictive factor of hospital readmission and survival in cirrhosis. PLoS ONE 2016, 11, e0157371. [CrossRef] [PubMed]

46. Ye, S.; Zheng, M.; Hu, Y.; Wu, F.; Zhao, L.; Chen, Y. Hydrochloride pioglitazone decreases urinary monocyte chemoattractant protein-1 excretion in type 2 diabetics. Diabetes Res. Clin. Pract. 2010, 88, 247-251. [CrossRef] [PubMed]

47. Murray, P.J.; Wynn, T.A. Protective and pathogenic functions of macrophage subsets. Nat. Rev. Immunol. 2011, 11, 723-737. [CrossRef] [PubMed]

48. Li, C.; Ding, X.Y.; Xiang, D.M.; Xu, J.; Huang, X.L.; Hou, F.F.; Zhou, Q.G. Enhanced M1 and impaired M2 macrophage polarization and reduced mitochondrial biogenesis via inhibition of AMP kinase in chronic kidney disease. Cell Physiol. Biochem. 2015, 36, 358-372. [CrossRef]

49. Anders, H.J.; Ryu, M. Renal microenvironments and macrophage phenotypes determine progression or resolution of renal inflammation and fibrosis. Kidney Int. 2011, 80, 915-925. [CrossRef] [PubMed]

50. Di Gregorio, G.B.; Yao-Borengasser, A.; Rasouli, N.; Varma, V.; Lu, T.; Miles, L.M.; Ranganathan, G.; Peterson, C.A.; McGehee, R.E.; Kern, P.A. Expression of CD68 and macrophage chemoattractant protein-1 genes in human adipose and muscle tissues: Association with cytokine expression, insulin resistance, and reduction by pioglitazone. Diabetes. 2005, 54, 2305-2313. [CrossRef]

51. Shoyaib, A.A.; Archie, S.R.; Karamyan, V.T. Intraperitoneal route of drug administration: Should it be used in experimental animal studies? Pharm. Res. 2019,37, 12. [CrossRef]

52. Yoneda, M.; Honda, Y.; Ogawa, Y.; Kessoku, T.; Kobayashi, T.; Imajo, K.; Ozaki, A.; Nogami, A.; Taguri, M.; Yamanaka, T.; et al. Comparing the effects of tofogliflozin and pioglitazone in non-alcoholic fatty liver disease patients with type 2 diabetes mellitus (ToPiND study): A randomized prospective open-label controlled trial. BMJ Open Diabetes Res. Care 2021, 9, e001990. [CrossRef]

53. Satirapoj, B.; Watanakijthavonkul, K.; Supasyndh, O. Safety and efficacy of low dose pioglitazone compared with standard dose pioglitazone in type 2 diabetes with chronic kidney disease: A randomized controlled trial. PLoS ONE 2018, 13, e0206722. [CrossRef]

54. Eckland, D.A.; Danhof, M. Clinical pharmacokinetics of pioglitazone. Exp. Clin. Endocrinol. Diabetes 2000, 108, 234-242. [CrossRef]

55. Hanefeld, M. Pharmacokinetics and clinical efficacy of pioglitazone. Int. J. Clin. Pract. Suppl. 2001, 121, 19-22.

56. Mantovani, A.; Zaza, G.; Byrne, C.D.; Lonardo, A.; Zoppini, G.; Bonora, E.; Targher, G. Nonalcoholic fatty liver disease increases risk of incident chronic kidney disease: A systematic review and meta-analysis. Metabolism 2018, 79, 64-76. [CrossRef]

57. Byrne, C.D.; Targher, G. NAFLD as a driver of chronic kidney disease. J. Hepatol. 2020, 72, 785-801. [CrossRef]

58. Singal, A.K.; Hasanin, M.; Kaif, M.; Wiesner, R.; Kuo, Y.F. Nonalcoholic steatohepatitis is the most rapidly growing indication for simultaneous liver kidney transplantation in the United States. Transplantation 2016, 100, 607-612. [CrossRef]

59. Cusi, K.; Orsak, B.; Bril, F.; Lomonaco, R.; Hecht, J.; Ortiz-Lopez, C.; Tio, F.; Hardies, J.; Darland, C.; Musi, N.; et al. Long-term pioglitazone treatment for patients with nonalcoholic steatohepatitis and prediabetes or type 2 diabetes mellitus: A randomized trial. Ann. Intern. Med. 2016, 165, 305-315. [CrossRef] 
60. Yen, C.L.; Wu, C.Y.; See, L.C.; Li, Y.J.; Tseng, M.H.; Peng, W.S.; Liu, J.R.; Chen, Y.C.; Yen, T.H.; Tian, Y.C.; et al. Pioglitazone reduces mortality and adverse events in patients with type 2 diabetes and with advanced chronic kidney disease: National cohort study. Diabetes Care 2020, 43, 152-153. [CrossRef]

61. Nampoothiri, R.V.; Duseja, A.; Rathi, M.; Agrawal, S.; Sachdeva, N.; Mehta, M.; Dhaliwal, H.S.; Dhiman, R.K.; Chawla, Y. Renal dysfunction in patients with nonalcoholic fatty liver disease is related to the presence of diabetes Mellitus and severity of Liver Disease. J. Clin. Exp. Hepatol. 2019, 9, 22-28. [CrossRef] 